\title{
Dental Attrition
}

National Cancer Institute

\section{Source}

National Cancer Institute. Dental Attrition. NCI Thesaurus. Code C94544.

The loss of tooth structure by mechanical forces from opposing teeth. 